\title{
Fast Change: Immersive Self-Development Strategies for Everyday Life
}

\author{
Eric Pappas, Rosealie Lynch, Jesse Pappas, Mariah Chamberlin \\ James Madison University \\ Email: pappasec@jmu.edu
}

\begin{abstract}
Some of the greatest thinkers of our time have argued that among the most valuable human skills is the ability to change one's self at will. In the two studies described here, we address questions about the purpose, practice, and consequences of an immersive, week-long intentional selfdevelopment project intended to produce durable and lasting positive changes in the self. The objective of the current research was to examine the immediate and longer-term effects of an original self-development intervention that uses cognitive dissonance (the tension produced by the lack of alignment between one's values and behaviors) to motivate and sustain a series of intentional changes made in the service of becoming one's "ideal self" across all life contexts for one full week. Our results show promising evidence that the methodology we have developed leads to students' progress in the areas of awareness, motivation, and intentional self-development.
\end{abstract}

Keywords: Cognitive dissonance, individual sustainability, intentional self-development, cognitive behavioral change.

\section{Introduction}

The perpetual struggle to improve one's self is fundamentally human. In terms of scientific, methodical research, however, we know very little about the mechanisms that underpin intentional change in daily life - this is especially true of the fast, immersive variety of self-development that may, under the right conditions, profoundly alter a personality in a matter of minutes. If more was known about the fundamentals of intentional change, we might be better at teaching our students how to coax the best out of themselves and live up to their ideals. What factors can facilitate a radical redesign of the selfconcept? Why do some individuals thrive in self-improvement scenarios while others struggle? Popular commercial (self-help) approaches to personal development are notorious for over-promising and underdelivering. Even so, many among us continue to eagerly invest in anyone who can sell us a better version of ourselves, however unlikely that might be.

Thoughtfully planned and methodically executed approaches to incremental cognitive and behavioral change are well-represented in the academic literature (see Prochaska \& Velicer 1997; Brandtstädter 1998; Baltes \& Baltes 1990; Pappas \& Pappas 2011, and others). On the other hand, the consequences of a high speed, fully immersed, "shotgun-style" approach to intentional self-development have yet to be examined. For this reason, it was difficult to predict what effect (if any) the immersive, semi-structured interventions we deployed in the present studies would have on student self-concept and behavior. Two authors' intentional self-development research program spans almost two decades, and previous efforts have involved refined interventional methodologies for enabling positive change in an individual over a period of 10-12 weeks (Pappas \& Pappas 2011). ${ }^{1}$

The objective of this exploratory research was to examine the immediate and longer-term effects of an original self-development intervention that uses cognitive dissonance to motivate a series of intentional changes made in the service of becoming one's "ideal self" across many life contexts for one full week. Behavior, because of its naturally reinforcing nature, is at the center of resistance to change as well as imperative to reducing or eliminating cognitive dissonance. Our research employed cognitive dissonance

${ }^{1}$ Pappas, J. \& Pappas, E. (2015); Nagel, R., Pappas, E., Swain, M. and Hazard, G. (2015); Pappas, E. (2013); Nagel, R., Pappas, E. \& Hazard, G. (2014); Pierrakos, O., Nagel, R., Pappas, E., Nagel, J. Moran, T., Barrella, E. and Panizo, M. (2013); Benton, M., Pappas, J. \& Pappas, E. (2011); Pappas, E. (2011) 
that was intentionally introduced into a setting and focused on the alignment of students' stated values and their demonstrated behaviors.

The immersive nature of this intervention allows participants to make dramatic changes to their behavior and immediately begin to experience how it feels to live in accordance with their ideals. The results of the two studies described here indicate that deploying intentional self-development skills in a motivation-rich, immersive environment enabled many participants to develop new habits and situational identities that continue to serve them in academic, personal, and professional contexts. Our sub-objectives for this research: during the course of one week, our students would:

1) Articulate a vision of their ideal selves,

2) Learn and deploy processes that enable intentional change,

3) Develop and execute a personal intentional change strategy,

4) Identify and engage barriers to intentional change, and

5) Create durable intentional self-development habits.

To this point, our work on fast change has been exploratory, so we emphasize observations over claims and plan to report more targeted outcomes in subsequent studies.

\section{$2 \quad$ Literature Review}

Intentional self-development has occupied the minds of philosophers and psychologists for centuries, and the standard for intentional self-development has been the "slow change" process, characterized by careful planning, monitoring progress, and evaluating gains.

\subsection{Theories of Intentional Self-Development and Intentional Change}

Rogers (1951) considered the motivation behind intentional self-development "...to actualize, maintain, and enhance the experiencing organism" (p.487) and centered much of his philosophy and change processes methodology on living as "individuals in process" (1969, p.105). Maslow (1968) also discussed intentional self-development - self-actualization - as the key to individual growth and change; he described the "self as a project" (pg.12) - a phrase more often attributed to Sartre -in which intentional change processes allowed the increasingly self-actualized individual to "...make himself into anything he decided to be" (p.12).

The contributions of Brandtstädter's (1999) developmental systems theory are central to the body of research on individual change. According to Brandtstädter (1998), reflective thought and intentional control of behaviors help create a desired behavioral change towards achieving a goal. Baltes and Baltes (1990) and Freund et al. (1999) noted that, through the consequences of intentional actions, individuals develop guides (motivations, intentions) for further goal-oriented action.

In the 1950s, Julian Rotter (1954), a pioneer in social learning theory, explained that individuals are motivated by positive stimulation as a means of avoiding negative stimulation. Others, including Rotter (1966), Schultz \& Heckhausen (1996), and Morf \& Horvath (2010) stressed intentional self-development as a means for improving both cognitive and affective abilities. Gestsdottir \& Lerner (2008) referred to these developmental processes as "intentional self-regulation"-actions aimed towards harmonizing personal goals in order to enhance self-development.

\subsection{Cognitive Dissonance}

Over the last four years, our research has focused on using cognitive dissonance between values and behaviors as a catalyst for self-development. Cognitive dissonance, first described by Festinger (1957), is a tension-producing psychological situation arising from inconsistent knowledge. In his original theory, Festinger (1957) outlines three factors central to creating cognitive dissonance in an individual: 1) having to choose between alternatives, 2) the existence of a behavior one might normally avoid, and 3) the occurrence of new information. Wicklund and Brehm (1976) note that changing one of the dissonant variables, or rendering it irrelevant, is key to the dissonance reduction process; this can be accomplished "by changing the behavioral element" (p.5). Brehm and Cohen (1962) also noted that behavioral commitment was not simply a central factor in reducing dissonance, but a necessary condition. 
Dissonance reduction in the form of active decisions or changed behaviors tends to persist, in some form or other, according to Wicklund and Brehm (1976), even years following the event, since maintaining such a cognitive state was not subject to continued motivation.

\subsection{Immersive Experiences}

Jackson \& Campbell (2014) conducted two studies investigating the nature of immersive experiences and the transformational impact immersion can have on one's sense of self and identity. Their results indicate that immersive experiences represent fertile ground for the pursuit of self-development goals and an ideal environment for facilitating fast changes to the self-concept. A partial list of effects immersive experiences may have on the self follows:

1. Immersive experiences often relay a sense of personal change, growth, and gain.

2. Immersive situations often stimulate and require reflection and discovery of self.

3. People gain new insights on complex lives, and these insights may well connect with or change a person's identity.

4. People in immersive situations often change their value systems and become more humble.

5. People become more self-aware and gain confidence in their own capability, often through the support of others and reflection leading to recognition of one's ability. (Jackson \& Campbell 2014)

Among the research studies conducted on behavioral and cognitive immersion, Giambatista and Hoover's (2014) research focused on cognitive and emotional skills, and found that behavioral immersion environments are "likely to generate improved behavioral skill acquisition of executive skills" (p.1).

Immersion clinical experiences have resulted in dramatic affective changes in students' values and attitudes (Neander \& Markle 2005).

\section{Methodology}

In this 2015 University IRB approved research, we employed cognitive dissonance as a motivator for individual change in a process designed to reveal how students' behaviors did not align with their stated values in two studies. Our participants in the first study (referred to as Study 1) included 29 upper-class students in an experimental social psychology class and, in a second study (Study 2), 235 students in an introductory level science and technology problem solving class. Each study combines two semesters' worth of students in the respective courses.

Following three reflective writing assignments in which students reflected on their identities and evaluated the alignment of their behaviors and values, they were directed to "be" or "embody" their "ideal selves" in all situations in which they found themselves for an entire week. ${ }^{2}$ As noted in the Introduction, the goal of this study was to test whether the methodology would create sufficient levels of self-awareness and motivation for students to create enduring personal changes during a one-week immersive experience.

Leading up to the week-long "Fast Change Project," students compared two essays they composed, the first describing their "real selves" and one (written a week later) describing their "ideal selves." The contexts of self in which students described themselves were those referred to as Sustainable Personality (or Individual Sustainability): intellectual, social, philosophical, physical, and emotional, as described in Pappas, Pappas, and Sweeny (2014), and McDearis and Pappas (2014). Students were then instructed to write a third paper analyzing the differences between their real and ideal selves, and identify any obstacles they faced to adopting ideal self behaviors. We designed this assignment to elicit and require students to reflect upon, cognitive dissonance.

Students were not informed of the concept of cognitive dissonance prior to the project, nor were they informed as to the purpose of the research. The context of the classes, however, is behavioral change, so students were not disturbed by the assignments, realizing that much of the work in these classes was unfamiliar and challenging.

${ }^{2}$ Visit http://www.frontiersinsustainability.com/ for specific directions on assignments during each phase of intervention. 
Six weeks after they completed the project, students in both classes took a follow-up Qualtrics-based survey comprised of a combination of open and fixed response items. In Study 2 (235 students), we also incorporated a longitudinal component in which participants completed a survey six months later, which measured continued project outcomes with a specific focus on how durable the intentional changes had been over the time period.

All papers and the primary survey were required, for-credit course assignments; however, we emphasized that students would receive full credit for the simple completion of these assignments, and personal outcome would not positively or negatively affect their grade on the project. To ensure a sufficiently immersive and well-structured experience, students adhered to strict deadlines or else their work was excluded from the study. Those who failed to turn in any assignment, including any of the nightly journal papers written during the week of Fast Change, were similarly excluded. ${ }^{3}$ Excluding tardy participants provided an essential manipulation check of sorts, as late and missing work indicated general disengagement with the strict study protocol.

In both studies, student responses were submitted in electronic folders and included the following:

1. Three personal essays as "preparation" (real self, ideal self, analysis of these first two papers);

2. Six nightly journals during the week of the Fast Change Project;

3. A final reflection in essay format on Day 7 ("Fast Change Project Final Analysis");

4. Responses to an online follow-up survey completed six weeks after the project had ended; and

5. In Study 2 (235 students), a second follow-up survey conducted six months following the project, when participants were no longer in our class.

Following both studies, we compiled data collected from the consecutive courses (Spring and Fall 2015 semesters) and determined how many students would qualify for inclusion in our study based on their full participation in each of the required stages of the project. ${ }^{4}$

First, the authors coded the students' narrative responses - their "Fast Change Project Final Analysis" - into major categories that emerged while reading through the data (Durability, Unexpected Ease of Making Changes, Increased Satisfaction, Identity Formation, Success in the Project, Difficulty in the Project, and Third-Party Recognition). Being aware of the shortcomings of self-report, we coded students' comments in their free-form Final Analyses conservatively, requiring language that was very specific to the themes as they emerged.

Second, the authors reviewed the survey data to assess how students' perceptions changed in the six weeks following the intervention and to determine if outcomes had evolved. To this end, we report only on a sample of survey questions that best aligned with the coded categories that emerged in narrative responses. To organize our results, we report first on each coded narrative response category, and then on student responses to the corresponding survey questions.

Our results in the section below are organized as follows:

Study 1 (n=29): Durability, Unexpected Ease of Making Changes, Increased Satisfaction, Identity Formation, Success in the Project, Difficulty of the Project, and Third-Party Recognition.

Study 2 ( $n=235)$ : Durability, Unexpected Ease of Making Changes, Increased Satisfaction, Identity Formation, and Success in the Project, Third-Party Recognition, ${ }^{5}$ Students Who Did Not Succeed. ${ }^{6}$

Study 2: Longitudinal Portion ( $n=49)$ : Durability, Unexpected Ease of Making Changes, Increased Satisfaction, and Identity Formation.

\footnotetext{
${ }^{3}$ Of the 38 students in the upper-level class in Study 1, nine were omitted for one or more of the above reasons, leaving 29 participants. Of the 295 students participating in Study 2, 235 qualified under these conditions.

${ }^{4}$ The only exception to this rule was the longitudinal follow-up study with participants from Study 2, who were no longer in our class (in this case, 49 out of the 235 students volunteered participation).

${ }^{5}$ We did not code the 235 narrative responses for Third-Party Recognition in Study 2, and report results only from survey responses for this category.

${ }^{6}$ We based results in this category on narrative responses to the survey that described students' challenges and/or negative experiences in an attempt to better understand the conditions that limit student success. Too few students in Study 1 reported difficulties to warrant a consideration of this category.
} 


\section{Results}

\subsection{Results of Study 1}

The following are results from the initial study of 29 students who were enrolled in an upper-level experimental social psychology course: Sustainable Personality. We report results from two sources: 1) Themes that emerged from coded narrative responses from students written at the end of the Fast Change week, and 2) Qualtrics survey responses from the same students six weeks later. We report these narrative responses from the Fast Change Project Final Analyses immediately following each subheading, with a table showing the Qualtrics survey results from questions that corresponded to each theme directly below.

\subsubsection{Durability}

1. Coded Responses: Sixteen out of 29 students (55\%) recorded unsolicited comments about the longevity of their changes - that students expected changes to last beyond the week-long project. Of these 16 responses, nine students reported some confidence in their ability to maintain their newly established changes in behavior, while an additional seven students commented about the durability of an enduring mindset of personal growth.

2. Survey Results: Table 1 shows survey results for "Durability."

Table 1. Survey Results for Durability in Study 1 (Survey conducted six weeks after intervention)

\begin{tabular}{|c|c|}
\hline Survey Question & Survey Responses $(\mathrm{N}=29)$ \\
\hline $\begin{array}{l}\text { \#9. Are you still "doing" the project? } \\
\text { [fixed response] }\end{array}$ & $\begin{array}{l}\text { Yes }-11 \\
\text { Somewhat-16 } \\
\text { No-2 }\end{array}$ \\
\hline $\begin{array}{l}\# 10 . \text { Briefly explain if you are still doing the project... } \\
\text { [open response] }\end{array}$ & $\begin{array}{l}23 \text { out of } 29 \text { responses indicated they were continuing the } \\
\text { project }\end{array}$ \\
\hline $\begin{array}{l}\# 11 \text {. How often do you still carry out these "ideal self" } \\
\text { behaviors? [fixed response] }\end{array}$ & $\begin{array}{l}\text { Most of the time- }-15 \\
\text { Neutral-9 } \\
\text { Seldom }-5\end{array}$ \\
\hline $\begin{array}{l}\text { \#31. How often do you STILL think about your ideal self } \\
\text { (e.g., Ask yourself "What would my ideal self do?) [fixed } \\
\text { response] }\end{array}$ & $\begin{array}{l}\text { Most of the time }-4 \\
\text { Often-10 } \\
\text { Neutral-10 } \\
\text { Seldom-4 } \\
\text { Never }-1\end{array}$ \\
\hline
\end{tabular}

\subsubsection{Unexpected Ease of Making Changes.}

1. Coded Responses: In the narrative responses immediately following the week of Fast Change, we coded "It was easier than I thought [to be my ideal self]" in 14 out of 29 responses (or 55\%).

2. Survey Results: Table 2 shows survey results for "Unexpected Ease."

Table 2. Survey Results for Unexpected Ease of Making Changes in Study 1 (Survey conducted six weeks after intervention)

\begin{tabular}{l|l}
\hline Survey Question & Survey Responses $(\mathrm{N}=29)$ \\
\hline
\end{tabular}

${ }^{7}$ Percentages are rounded to the nearest percentage point and may not add up precisely to 100 for each survey question. 
\#14. If you are still continuing the project, why are you continuing? (check any that apply)

\subsubsection{Increased Satisfaction}

1. Coded Responses: We coded 12 student written responses (41\%) for "I felt better about myself." Of these 12 responses, seven students reported a greater sense of self-satisfaction or accomplishment during the project, while six reported greater levels of day-to-day satisfaction.

2. Survey Results: Table 3 shows survey results for "Increased Satisfaction."

Table 3. Survey Results for Increased Satisfaction in Study 1 (Survey conducted six weeks after intervention)

\begin{tabular}{|c|c|c|}
\hline Survey Question & Survey Responses $(\mathrm{N}=29)$ & \\
\hline $\begin{array}{l}\text { \#13. How did completing this project make you feel } \\
\text { about yourself? [fixed response] }\end{array}$ & $\begin{array}{l}\text { Much better about myself }-9 \\
\text { Somewhat better about myself-11 } \\
\text { Neutral— } 5 \\
\text { Somewhat worse about myself }-4\end{array}$ & $\begin{array}{l}(31 \%) \\
(38 \%) \\
(17 \%) \\
(14 \%)\end{array}$ \\
\hline $\begin{array}{l}\text { \#14. If you are still continuing the project, why are you } \\
\text { continuing? }\end{array}$ & $\begin{array}{l}\text { I feel better about myself-19 } \\
\text { I feel better/more comfortable... } \\
\text {...Emotionally-19 } \\
\text {..Physically-19 } \\
\text {...Socially-16 } \\
\text {...Intellectually-15 }\end{array}$ & $\begin{array}{l}(66 \%) \\
(66 \%) \\
(66 \%) \\
(55 \%) \\
(52 \%)\end{array}$ \\
\hline
\end{tabular}

\subsubsection{Identity Formation}

1. Coded Responses: Out of 29 narrative responses, 34\%, or ten students, wrote about identity formation. We identified four sub-categories when coding for identity formation: six students reported greater self-awareness; five reported values clarification; three reported greater selfconfidence; and five reported a greater understanding of their ideal self.

2. Survey Results: Table 4 shows survey results for "Identity Formation."

Table 4. Survey Results for Identity Formation in Study 1 (Survey conducted six weeks after intervention)

\begin{tabular}{l|lr}
\hline Survey Question & Survey Responses (N=29) & $(34 \%)$ \\
\hline \#6. Was this project helpful in developing a vision for & Extremely helpful-10 & $(34 \%)$ \\
yourself and who you want to be? [fixed response] & Very helpful-10 & $(31 \%)$ \\
& Somewhat helpful-9 & $(3 \%)$ \\
\hline \#27. How did your understanding of your ideal self & No change-1 & $(7 \%)$ \\
change over the course of the week-long project? [fixed & Little change-2 & $(3 \%)$ \\
response] & Neutral-1 & $(62 \%)$ \\
& Some change-18 & $(21 \%)$ \\
\hline
\end{tabular}

\subsubsection{Success in the Project}

1. Coded Responses: Fifteen of the 29 responses (52\%) indicated that students felt the project was successful for them. Of these responses, we identified an additional subcategory: six students $(23 \%)$ reported greater self-awareness.

2. Survey Results: Table 5 shows survey results for "Success in the Project." 
Table 5. Survey Results for Success in the Project in Study 1 (Survey conducted six weeks after intervention)

\begin{tabular}{l|lr}
\hline Survey Question & Survey Responses $(\mathrm{N}=29)$ & $(3 \%)$ \\
\hline$\# 17$. Overall, how successful was the Fast Change & Extremely successful-1 & $(45 \%)$ \\
Project for you? [fixed response] & Very successful-13 & $(48 \%)$ \\
& Somewhat successful-14 & $(3 \%)$ \\
\hline
\end{tabular}

\subsubsection{Difficulty of the Project}

1. Coded Responses: Out of 29 narratives, 17 (57\%) noted the difficulty of this week-long assignment. Of these 17, three explanations for the project's difficulty emerged: five students reported difficulties with the assignment's degree of immersion, five reported an initial struggle followed by the project becoming much easier, and three reported over thinking as a major challenge.

2. Survey Results: Table 6 shows survey results for "Difficulty of the Project."

Table 6. Survey Results for Difficulty of the Project in Study 1 (Survey conducted six weeks after intervention)

\begin{tabular}{l|lr}
\hline Survey Question & Survey Responses $(\mathrm{N}=29)$ & $(3 \%)$ \\
\hline $\begin{array}{l}\text { \#5. How difficult was the project for you? } \\
\text { [fixed response] }\end{array}$ & $\begin{array}{l}\text { Extremely difficult-1 } \\
\text { Very difficult-6 } \\
\text { Somewhat difficult-18 } \\
\text { Not very difficult-4 }\end{array}$ & $(62 \%)$ \\
& $(14 \%)$ \\
\hline $\begin{array}{l}\text { \#12. What challenges did you face during the project? } \\
\text { (Check those that apply) }\end{array}$ & $\begin{array}{l}\text { I struggled to be my ideal self across all the contexts of } \\
\text { individual sustainability-23 } \\
\text { (10 options, including: forgetting about the project, } \\
\text { stress levels, scheduling difficulties, discomfort with } \\
\text { changes to routine, social pressure, motivation) }\end{array}$ & $\begin{array}{l}\text { I struggled with deciding what my ideal self would do in } \\
\text { the moment-to-moment-18 }\end{array}$ \\
\hline
\end{tabular}

\subsubsection{Third Party Recognition}

1. Coded Responses: In unsolicited responses, two out of 29 students (roughly 7\%) noted that friends or family members offered compliments during their week of Fast Change, suggesting recognition of improved behavior or personality changes.

2. Survey Results: Table 7 shows results for "Third Party Recognition."

Table 7. Survey Results for Third Party Recognition in Study 1 (Survey conducted six weeks after intervention)

\begin{tabular}{l|l}
\hline Survey Question & Survey Responses $(\mathrm{N}=29)$ \\
\hline $\begin{array}{l}\text { \#21. "Did others notice the changes you made? If so, } \\
\text { who are they? How do you know they noticed? [open } \\
\text { response] }\end{array}$ & $\begin{array}{l}14 \text { out of } 29 \text { students noted specific circumstances in } \\
\text { which others had commented on, or offered compliments } \\
\text { for, changes they were making. }\end{array}$ \\
\hline
\end{tabular}

\subsection{Results of Study 2}

Study 2 included 235 students enrolled in an introductory science and technology course: Problem Solving Approaches in Science and Technology. As with Study 1, we report results from two sources: 1) Themes that emerged from coded narrative responses from students written at the end of the Fast 
Change Project, and 2) Qualtrics survey responses from the same students six weeks later. Again, as with Study 1, we report these narrative responses from the Fast Change Project Final Analyses immediately following each sub-heading, with a table showing the survey results from questions that correspond to each theme directly below.

\subsubsection{Durability.}

1. Coded Responses: In their end-of-week narrative analyses of the project, 127 out of 235 (54\%) students included indications of sticking with the changes they had made.

2. Survey Results: Table 8 shows survey results for "Durability."

Table 8. Survey Results for Durability in Study 2 (Survey conducted six weeks after intervention)

\begin{tabular}{|c|c|}
\hline Survey Question & Survey Responses $(\mathrm{N}=235)$ \\
\hline \#25. Are you still "doing" the project? [fixed response] & $\begin{array}{l}\text { Yes }-43 \\
\text { No-13 } \\
\text { Somewhat }-179\end{array}$ \\
\hline $\begin{array}{l}\text { \#30. Briefly explain if or how you are still doing the } \\
\text { project.... }\end{array}$ & $\begin{array}{l}216 \text { out of } 235 \text { students' responses indicated they were } \\
\text { either continuing some habits or continually questioning } \\
\text { whether their values and behaviors align. } \\
(92 \%)\end{array}$ \\
\hline $\begin{array}{l}\text { \#27. How often do you still carry out these "ideal self" } \\
\text { behaviors (or "better self," if you like)? [fixed response] }\end{array}$ & $\begin{array}{l}\text { All the time }-5 \\
\text { Most of the time- }-135 \\
\text { Neutral }-77 \\
\text { Seldom }-14 \\
\text { Not at all }-2\end{array}$ \\
\hline $\begin{array}{l}\text { \#3. How often do you still think about your ideal self? } \\
\text { (i.e. ask yourself "What would my ideal self do?" or } \\
\text { "What would my better self have done?") [fixed response] }\end{array}$ & $\begin{array}{l}\text { Most of the time }-29 \\
\text { Often-105 } \\
\text { Neutral-57 } \\
\text { Seldom-40 } \\
\text { Never }-4\end{array}$ \\
\hline
\end{tabular}

\subsubsection{Unexpected Ease of Making Changes}

1. Coded Responses: In their narrative-form final analyses, 62 out of 235 students, or $26 \%$, commented on how the project was easier than they had anticipated.

2. Survey Results: Table 9 shows survey results for "Unexpected Ease."

Table 9. Survey Results for Unexpected Ease of Making Changes in Study 2 (Survey conducted six weeks after intervention)

\begin{tabular}{l|l}
\hline Survey Question & Survey Responses $(\mathrm{N}=235)$ \\
\hline \#26. If you are still doing the project, why are you & It is easier to continue than I thought it would be-126 \\
continuing? [Check any that apply] & \\
\hline
\end{tabular}

\subsubsection{Increased Satisfaction.}

1. Coded Responses: In the end-of-week narrative analyses, 161 out of 235 students, roughly $68 \%$, reported feeling better about themselves as a result of the Fast Change Project.

${ }^{8}$ Percentages are rounded to the nearest percentage point and may not add up to 100 for each survey question. 
2. Survey Results: Table 10 shows survey results for "Increased Satisfaction."

Table 10. Survey Results for Increased Satisfaction in Study 2 (Survey conducted six weeks after intervention)

\begin{tabular}{l|ll}
\hline Survey Question & Survey Responses $(\mathrm{N}=235)$ & \\
\hline \#10. How did completing this project make you feel & Much better about myself-72 & $(31 \%)$ \\
about yourself? & Somewhat better about myself-120 & $(51 \%)$ \\
& Neutral-25 & $(11 \%)$ \\
& Somewhat worse about myself-25 & $(11 \%)$ \\
\hline \#26. If you are still doing the project, why are you & I feel better about myself-163 & $(69 \%)$ \\
continuing? [Check any that apply] & I feel better/more comfortable... & $(57 \%)$ \\
& ...Emotionally-134 & $(65 \%)$ \\
& ...Physically-152 & $(59 \%)$ \\
& ...Socially-139 & $(54 \%)$ \\
\hline
\end{tabular}

\subsubsection{Identity Formation.}

1. Coded Responses: We coded 187 student responses (80\%) with comments pertaining to basic identity growth as a result of the project.

2. Survey Results: Table 11 shows survey results for "Identity Formation."

Table 11. Survey Results for Identity Formation in Study 2 (Survey conducted six weeks after intervention)

\begin{tabular}{l|lr}
\hline Survey Question & Survey Responses $(\mathrm{N}=235)$ & \\
\hline \#21. Was this project helpful in developing a vision for & Extremely helpful-58 & $(25 \%)$ \\
yourself and who you want to be? [selective response] & Very helpful-119 & $(51 \%)$ \\
& Somewhat helpful-52 & $(22 \%)$ \\
& Not very helpful-5 & $(2 \%)$ \\
& Not at all helpful-1 & $(0 \%)$ \\
\hline \#28. How did your understanding of your ideal self & No change-8 & $(3 \%)$ \\
change over the course of the week-long project? & Little change-34 & $(14 \%)$ \\
[selective response] & Neutral/undecided-36 & $(15 \%)$ \\
& Some change-115 & $(49 \%)$ \\
& Substantial change-39 & $(17 \%)$ \\
\hline
\end{tabular}

\subsubsection{Success in the Project}

1. Coded Responses: In their end-of-week narratives, 172 out of 235 (73\%) students reported they had successfully embodied their Ideal Self or made positive changes in that direction.

2. Survey Results: Table 12 shows survey results for "Success in the Project."

Table 12. Survey Results for Success in the Project in Study 2 (Survey conducted six weeks after intervention)

\begin{tabular}{l|l}
\hline Survey Question & Survey Responses $(\mathrm{N}=235)$ \\
\hline
\end{tabular}


\#20. Overall, how successful was the Fast Change Project for you? [selective response]
Extremely successful一29

Very successful-112

Somewhat successful-88

Not very successful-4

Not at all successful-1
$(12 \%)$

\subsubsection{Students Who Did Not Succeed}

In order to further investigate why some students did not successfully implement changes in accordance with their ideal selves, we coded students' negative comments about their experiences from two open-ended questions in the survey ("Explain if you are continuing the project..." and "Did your experience meet your expectations?").

Survey results: Of the 235 participants, 26 students (or 11\%) responded negatively to the Fast Change Project. Eight students reported a "lack of clarity" as a major obstacle. An additional eight students cited outside distractions, forgetfulness, busy schedules, and peer pressure as insurmountable hurdles to acting like their ideal selves. Lack of motivation was cited by three students, while three others noted a general feeling of disappointment with their progress.

\subsubsection{Third Party Recognition}

While we did not code for third-party recognition in the narrative responses (recognizing its low frequency in the previous study), we included a survey question specifically soliciting feedback of this kind.

Survey Results: Of 235 participants, $147(63 \%)$ responded affirmatively to "Did others notice some of the changes you made?"...that others (friends, family, etc.) had clearly recognized the changes they made. The other $82(35 \%)$ reported no, either they had not received any reports of third-party recognition or were unsure if anyone noticed their changes.

\subsection{Results of Study 2: Longitudinal Study (Six Months Later)}

These results are from the final, follow-up survey of 235 students six months after their participation in Study 2. Considering students were no longer enrolled in our course, only 49 of the original pool of 235 qualifying participants (21\%) volunteered participation.

Results are organized by four of the same themes that emerged during Study 1 and Study 2, which we identified as most pertinent to our investigation of the Fast Change Project. Survey results are reported in tables under each theme.

\subsubsection{Durability}

Survey Results: Table 13 shows survey results for "Durability."

Table 13. Longitudinal Survey Results for Durability in Study 2 (Survey conducted six MONTHS after intervention)

\begin{tabular}{l|lc}
\hline Survey Question & Survey Responses (N=49) & \\
\hline \#2. Are you still "doing" the project (in one form or & Yes-34 & $(69 \%)$ \\
another)? [fixed response] & No-14 & $(29 \%)$ \\
\hline \#12. To this day, do you continue to act like your ideal & Only 39 out of 49 total survey respondents & $(80 \%)$ \\
self, as defined during the Fast Change Project? [open & answered this question. Their open-ended responses break \\
response] & $\begin{array}{l}\text { down into the following categories: } \\
\text { Yes, with durable behavior change-23 }\end{array}$ & $(47 \%)$ \\
& $\begin{array}{l}\text { Yes, with durable mindset change-9 } \\
\text { Not much durable change-4 } \\
\text { No durable change-3 }\end{array}$ & $(18 \%)$ \\
& & $(6 \%)$ \\
\hline
\end{tabular}




\begin{tabular}{l|lr}
\hline \#27. How often do you still intentionally behave like & Never-0 & $(0 \%)$ \\
your "ideal self" as defined during the Fast Change & Rarely-4 & $(14 \%)$ \\
Project? [fixed response] & Sometimes-27 & $(55 \%)$ \\
& Often-17 & $(35 \%)$ \\
& All the Time-0 & $(0 \%)$ \\
\hline \#8. How often do you still think about your ideal self? & All the time-5 & $(10 \%)$ \\
(i.e. Ask yourself "What would my ideal self do?") [fixed & Most of the time-11 & $(22 \%)$ \\
response] & Sometimes-21 & $(43 \%)$ \\
& Seldom-9 & $(18 \%)$ \\
\hline \#13. Has your behavior changed permanently because of & Yes-33 & $(4 \%)$ \\
the Fast Change Project? [fixed response] & No-15 & $(67 \%)$ \\
& {$[1$ no response] } & $(31 \%)$ \\
\hline
\end{tabular}

\subsubsection{Unexpected Ease of Making Changes.}

Survey Results: Table 14 shows survey results for "Unexpected Ease."

Table 14. Longitudinal Survey Results for Unexpected Ease of Making Changes in Study 2 (Survey conducted six MONTHS after intervention)

\begin{tabular}{l|l}
\hline Survey Question & Survey Responses $(\mathrm{N}=49)$ \\
\hline \#26. If you are still doing the project, why are you & It is easier to continue than I thought it would be-28 \\
continuing? [Check any that apply] & \\
\hline
\end{tabular}

\subsubsection{Increased Satisfaction.}

Survey Results: Table 15 shows survey results for "Increased Satisfaction."

Table 15. Longitudinal Survey for Increased Satisfaction in Study 2 (Survey conducted six MONTHS after intervention)

\begin{tabular}{l|lr}
\hline Survey Question & Survey Responses $(\mathrm{N}=49)$ & \\
\hline \#4. If you are still doing the project, why are you & I feel better about myself-39 & $(80 \%)$ \\
continuing? [Check any that apply] & I feel better/more comfortable... & $(59 \%)$ \\
& ...Emotionally-29 & $(59 \%)$ \\
& ...Physically-29 & $(59 \%)$ \\
& ...Socially-29 & $(43 \%)$ \\
\hline
\end{tabular}

\subsubsection{Identity Formation.}

Survey Results: See Table 16 below for survey results relating to "Identity Formation."

Table 16. Longitudinal Survey for Identity Formation in Study 2 (Survey conducted six MONTHS after intervention) 


\begin{tabular}{l|lr}
\hline \#9. How much has your identity changed as a result of & Completely-1 & $(2 \%)$ \\
the Fast Change Project? [fixed response] & Very much-2 & $(4 \%)$ \\
& A lot-13 & $(27 \%)$ \\
& Some-16 & $(33 \%)$ \\
& A little bit-10 & $(20 \%)$ \\
& Almost not at all-2 & $(4 \%)$ \\
& Not at all-4 & $(8 \%)$ \\
\hline
\end{tabular}

\section{Discussion}

Our results reveal promising evidence that the methodologies developed for the "Fast Change Project" lead to significant progress in awareness, motivation, and intentional self-development.

\subsection{The Role of Cognitive Dissonance}

We employed cognitive dissonance as a catalyst for behavioral change, recognizing that changing a dissonance variable (in this case, a behavior conflicting with an ideal trait) is a strong, though challenging, method of dissonance reduction. The state of cognitive dissonance produces strong emotional tension for subjects which acts as a motivator.

For some of our research participants, this study may have presented this state of tension as they contemplated their failure to be a person of integrity - one who acts on principles - for the very first time. This shock can lead to longer periods of awareness and contemplation of these discrepancies. Draycott \& Dabbs (1998) suggest that, although the initial state of tension produced by cognitive dissonance lasts between only three to five minutes, the effects can linger while steadily declining for two or more weeks. These authors note, however, that reinstatement of the original condition is possible by reminding participants of their inconsistencies. We designed our intervention to intentionally cultivate the repeated reinstatement of dissonance with a series of written reflections and in-class discussions about their progress during the intervention week.

\subsection{Awareness and Motivation}

We believe that the success of cognitive dissonance as a motivating force in this study was dependent on two supporting components of our methodology: the immersive nature of the project through which students developed and maintained an increasingly heightened self-awareness, as well as the high-stakes nature of the assignment. Many students reported gaining a significant boost in self-awareness as they constantly reflected on their values and assessed whether they were achieving (or approaching) their "ideal self" targets. This did not always lead to successful attempts at change; however, students who later reported being unsuccessful in making behavioral changes nevertheless noted gaining the "reward" of doing the project in terms of increased self-awareness. They also reported becoming more mindful of their "subconscious thought processes" and discovering self-limiting beliefs that stood in the way of acting as their ideal selves would.

This project pushed students to break through personal barriers they may have otherwise avoided thanks to the high-stakes nature of the assignment; indeed, many students commented during class discussions that they needed the external motivation - a graded assignment-for undertaking these changes. The requirement of submitting nightly journals on their progress to earn credit kept them accountable.

\subsection{Difficulties Experienced by Students and Unsuccessful Change Attempts}

A trend in students' comments about the challenges they faced to being their ideal selves dealt with the overall immersive nature of the project. It was simply too consuming and overwhelming for some students to manage multiple, simultaneous changes effectively. Immersion led to other challenges as well, 
notably, that students struggled with overthinking and "over analysis" of their behaviors, which stifled their progress.

A related set of problems that many students experienced was a lack of clarity about their ideal self or what their ideal self would do. The greatest challenge students reported when surveyed after the intervention was being unable to balance their ideal self behaviors across all the contexts and lack of clarity about what their ideal selves would do in certain situations. These students may have spent less time devoted to developing a vision for their ideal selves prior to the project, or struggled to parse between competing standards for themselves.

Others (29 out of 264 students in both studies), however, had difficulty admitting to the changes they could have focused on making, potentially suggesting the presence of intellectual, social, or emotional barriers that contributed to their resistance to change.

\subsection{Students' Success in the Project}

By contrast, students who reported feeling successful during and at the project's completion also ranked favorably in the outcomes "Increased Satisfaction" and "Unexpected Ease of Making Changes." We believe these outcomes are closely related to one another in a self-reinforcing cycle. As students increased their self-awareness over the course of the week through reflective exercises, they became more acutely aware of how the changes they were implementing enhanced their daily experience. When changes were successfully executed, students felt a sense of achievement, and this positive boost to selfesteem would help them implement further changes. This would help explain why participants reported being surprised by how easily they could make (and sustain) changes after experiencing an initial challenge.

As added incentive for continuing their progress, $48 \%$ of students in Study 1 and $63 \%$ of students in Study 2 reported receiving encouraging feedback from friends or family who noticed some of the changes on which they had been working. Third party recognition was based on students' self-report.

\subsection{From Cognitive Dissonance to Cognitive Consonance}

We argue that students who experienced success in becoming more like their ideal selves over the course of the week initiated an energizing - and for some, perhaps novel-state of harmony between their values and behaviors. Such a state would bring with it the positive and oft-reported outcomes of improved satisfaction and the discovery that change making was easier than anticipated. While contemporary authors often refer to this state as attitude-behavior alignment (Zhou et al. 2009) or a related term, we will refer to it, as Festinger did in his foundational 1957 study, as "cognitive consonance," the contrary experience to cognitive dissonance. This term is not well-defined in the literature and is often used as if its definition is self-evident; however, we believe it is more than merely the absence of dissonance, but instead contains an added dose of accomplishment and encouragement from the discovery that one's values and behaviors are in strong - or increasingly strong - alignment. Thus, the experience of it hinges on both self-awareness and a relatively positive self-image.

We suspect, based on student reporting, that arousal from cognitive dissonance begins to fade during the course of the week of "Fast Change," as students start making small behavioral changes to decrease dissonance, and that the experience of cognitive consonance emerges and grows incrementally as they reflect on their progress in aligning their behaviors with their values. This feeling of consonance, even if unarticulated, may well serve as a powerful motivating force to help maintain personal changes even past the conclusion of the formal project because students feel good when they are able to act in ways closer to their ideal selves. The movement from dissonance to consonance may serve as a potent positive feedback loop for students, spurring them on to new levels of self-harmony. Those who were unable to sustain changes made at the beginning of the Fast Change Project may have experienced a relatively rapid decline in consonance and a return of tension-producing dissonance.

\subsection{Durability of Changes}

Of foremost interest to us in the assessment of our methodology's overall effectiveness is the durability of changes students made, our central research question being: Can "Fast Change" in a week-long 
intervention create lasting behavioral modifications and, perhaps even personality changes, for participants? Our results indicate a majority of students maintained some outcomes from the project six weeks later, and any durability in this regard signals that this intervention was successful in motivating and enabling students to begin a process of self-development that can be maintained over time and continued as an iterative approach to becoming more and more like one's ideal self.

\section{Conclusion}

Change yourself and improve your life in one week? It sounds like a crazy self-help claim, but the data suggest that for many it may be possible. All the aspirations, struggles, defeats, and victories that accompany such an immersive project as this seem to lead to greater levels of self-awareness and selfcontrol. While the durability of the changes students attempted during this project was of greatest interest to our research in order to ascertain the viability of fast, lasting personality change over the course of a single week, we feel there is significant value in teaching students how to recognize the cognitive dissonance created by conflicting values and behaviors, and to return to the process of rectifying this conflict at any point in the future.

The role of cognitive consonance is of great importance to this area of intervention, as the reinforcing shift from dissonance to consonance may serve as a self-reinforcing process for positive change. While we are confident that dissonance was the motivating trigger for change, we suspect that it may, in fact, be consonance, rather than dissonance, that kept students motivated during their week of fast change and beyond.

We believe the rapid successes our students experienced during this project can provide an effective foundation for self-developmental processes individuals can employ to advance their goals through intentional, well-integrated change efforts.

Acknowledgement. This material is based upon work supported by the National Science Foundation under Grant EEC \#1158728 (E. Pappas, PI). Any opinions, findings, and conclusions or recommendations expressed in this material are those of the authors and do not necessarily reflect the views of the National Science Foundation.

\section{References}

1. Baltes, P. B., \& Baltes, M. (1990). Psychological perspectives on successful aging: The model of selective optimization with compensation. In Baltes \& Baltes (Eds.), Successful aging perspectives from the behavioral sciences (pp. 48-69). New York: Cambridge University Press.

2. Benton, M., Pappas, J., \& Pappas, E. (2011). WordPress+Qualtrics: A plugin supporting research and new pedagogy to develop personal sustainability via $360^{\circ}$ evaluation. AMCIS 2011: 17th Americas Conference on Information Systems, Detroit, August.

3. Brandtstädter, J. (1998). Action perspectives on human development. In W. Damon \& R. M. Lerner (Eds.), Theoretical models of human development (5th ed., Vol. 1, pp. 807-863). New York: Wiley.

4. Brandtstädter, J. (1999). The self in action: Cultural, biosocial, and ontogenetic bases of intentional selfdevelopment. In J. Brandtstädter \& R. Lerner (Eds.), Action and self-development: Theory and research through the life span (pp. 37-67). Thousand Oaks, Ca.: Sage.

5. Brehm, J. S., \& Cohen, A. R. (1962). Explorations in cognitive dissonance. New York: Wiley.

6. Draycott, S., \& Dabbs, A. (1998). Cognitive dissonance 1: An overview of the literature and its integration into theory and practice in clinical psychology. British Journal of Clinical Psychology, 31, 341-353.

7. Festinger, L. (1957). A theory of cognitive dissonance. Evanston, Illinois: Row, Peterson.

8. Freund, A. M., Li, Z., \& Baltes, P. (1999). The role of selection, optimization, and compensation in successful aging. In J. Brandtstädter \& R. M. Lerner (Eds.), Action and development: Theory and research through the life-span (pp. 401-435). Thousand Oaks, California: Sage.

9. Gestsdottir, S., \& Lerner, R. M. (2008). Positive development in adolescence: The development and role of intentional self-regulation. Human Development, 51(3), 202-224. 
10.Giambatista, R. C., \& Hoover, J. D. (2014). An empirical test of behavioral immersion in experiential learning. Developments in Business Simulation and Experiential Learning, 36.

11.Jackson, N., \& Campbell, S. (2014) The nature of immersive experience. In Jackson \& Cooper (eds.). Lifewide learning, education \& personal development eBook.

12.Maslow, A. (1968). Toward a psychology of being. New York: Van Nostrand.

13.McDearis, K., \& Pappas, E. (2014). Individual sustainability (video). Journal of Cleaner Production, 86(1).

14.Morf, C., \& Horvath, S. (2010). Self-regulation processes and their signatures: Dynamics of the self-system. In R. Hoyle (Ed.), Handbook of personality and self-regulation (pp. 117-144). Malden, Mass.: Wiley-Blackwell.

15.Nagel, R., Pappas, E., Swain, M., \& Hazard, G. (2015). Understanding students' values toward individual behaviors when in an engineering group. International Journal of Higher Education, Vol. 4, No. 2.

16.Nagel, R., Pappas, E., \& Hazard, G. (2014). "Understanding how students' value the behaviors of individuals in engineering teams." ASEE National Conference, Indianapolis, Ind. June.

17.Neander, W., \& Markle, D. (2005). Improving the cultural competence of nursing students: Results of integrating cultural content in the curriculum and an international immersion. Journal of Nursing Education, Vol. 44, 5.

18.Pappas, E. (2011). A behavioral approach to building cognitive foundations for effective thought and action in a freshman critical thinking course. 2011 Frontiers in Education National Conference, October, Rapid City, S.D.

19.Pappas, E., \& Pappas, J. (2011). A dispositional behavioral approach to teaching cognitive processes that support effective thought and action. Innovative Higher Education, 36(5), 359-372.

20.Pappas, E. (2013). Individual sustainability: Preliminary research. Frontiers in Education 2012 National Conference, Oklahoma City, October.

21.Pappas, E., Pappas, J., \& Sweeney, D. (2014). Walking the walk: Conceptual foundations of the Sustainable Personality. Journal of Cleaner Production, 86, 323-334.

22.Pappas, J., \& Pappas, E. (2015). The Sustainable Personality: Values and behaviors in Individual Sustainability. International Journal of Higher Education. Vol. 4(1).

23.Pierrakos, O., Nagel, R., Pappas, E., Nagel, J. Moran, T., Barrella, E., \& Panizo, M. (2013). A mixed-methods study of cognitive and affective learning during a sophomore design problem-based service learning experience. International Journal for Service Learning in Engineering, 1-28.

24.Rogers, C. R. (1951). Client-centered therapy: Its current practices, implications, and theory. Boston, Mass.: Houghton-Mifflin.

25.Rogers, C. (1969). Freedom to learn. Columbus, Ohio: Merrill.

26.Rotter, J. B. (1954). Social learning and clinical psychology. New York: Prentice-Hall.

27.Rotter, J. B.(1966). Generalized expectancies for internal versus external control of reinforcements. Psychological Monographs, 80(1), 1-28.

28.Schultz, R., \& Heckhausen, J. (1996). A life-span model of successful aging. American Psychologist, 51(2), 702714.

29.Wicklund, R.A., \& Brehm, J. W. (1976). Perspectives on cognitive dissonance. Hillsdale, N.J.: Lawrence Erlbaum Associates.

30.Zhou, J., Wang, E., Dovidio, J., \& Yu G. The effects of structural consistency on attitude-intention and attitude-behavior relationships. Social Behavior and Personality, 2009, 37(6), 781-790. 